\title{
Doctors' self-reported physical activity, their counselling practices and their correlates in urban Trivandrum, South India: should a full-service doctor be a physically active doctor?
}

\author{
Lipika Patra, G K Mini, Elezebeth Mathews, K R Thankappan
}

Achutha Menon Centre for Health Science Studies (AMCHSS), Sree Chitra Tirunal Institute for Medical Sciences and Technology (SCTIMST), Trivandrum, Kerala, India

Correspondence to Dr K R Thankappan,

Achutha Menon Centre for Health Science Studies,

Sree Chitra Tirunal Institute for Medical Sciences and Technology, Trivandrum 695011, Kerala, India, kavumpurathu@yahoo.com/ thank@sctimst.ac.in

Accepted 19 May 2013 Published Online First 14 June 2013
CrossMark

To cite: Patra L, Mini GK, Mathews $\mathrm{E}$, et al. $\mathrm{Br}$ J Sports Med 2015;49: 413-416.
ABSTRACT

Background Doctors' self-reported physical activity (PA) is associated with their propensity for prescribing PA. Methods We surveyed 146 doctors (median age 42 years; men $58.9 \%$ ), selected by multistage random sampling. Information on demographic details, selfreported PA and counselling offered to their patients was collected using a pretested, structured, self-administered questionnaire. Multivariate logistic regression analysis was carried out to find the predictors of PA and PA counselling offered to the patients.

Results Moderate PA was reported by $37.7 \%$ (95\% $\mathrm{Cl} 29.8$ to 45.5 ) of the doctors and the remaining $62.3 \%$ reported being inactive. Doctors who were motivated to perform PA (OR 4.01, 95\% Cl 1.82 to 8.86), who used exercise equipment at home (OR 3.97, Cl 1.68 to 9.36) and who used a neighbourhood facility for PA (OR 2.36, $\mathrm{Cl} 1.11$ to 5.02 ) were more likely to perform moderate PA compared with their counterparts. $25 \%$ of the doctors always asked and advised their patients on PA. Doctors who believed that their own healthy lifestyle influenced advice practices (OR 9.13, Cl 2.49 to 33.41), who consulted less than 30 patients/day (OR 5.35, Cl 1.41 to 20.25) and who reported previous participation in sports activities (OR 4.22, Cl 1.77 to 10.04) were more likely to always ask and advise their patients on PA compared with their counterparts.

Conclusions A majority of the doctors in our study were inactive and did not ask or advise their patients on PA. Measures are warranted to enhance doctors' own $\mathrm{PA}$ and their counselling practices.

\section{INTRODUCTION}

WHO recognises physical inactivity as one of the leading risk factors for morbidity and premature mortality. ${ }^{1}$ Physical inactivity is one of the major causes of non-communicable disease (NCD) burden; the United Nations considered physical activity (PA) as a cornerstone for combating NCDs. The International Society for Physical Activity and Health has recommended seven investments that work for PA. ${ }^{2}$ One of these investments is PA and NCD prevention integrated into primary healthcare systems.

One of the promising strategies to make positive changes in the behaviour of patients as well as the general population is advocacy by the medical practitioners. Doctors offer a regular contact point with patients with chronic diseases; this creates a positive interaction through good communication, which fosters the development of trust between the doctors and patients. ${ }^{3} 4$ Doctors are considered as a trusted source of information by patients, a very important factor for compliance. ${ }^{5}$ However, many doctors are not asking, advising or prescribing exercise for their patients. ${ }^{6}$ Doctors' better personal habits were reported to improve patient counselling on PA. ${ }^{7}$ Physically active doctors were three times more likely to regularly promote $\mathrm{PA}$ in their patients. $^{9}$ Incorporation of PA counselling into routine patient visits was reported to be the first step towards raising the PA level of patients. ${ }^{10}$

India is the second most populous nation on earth and the problem of NCDs is well recognised. ${ }^{11}$ Little is known on the doctor's self-reported PA and counselling practices in India. ${ }^{12}$ Therefore, we undertook a survey of Indian doctors to investigate their levels of PA.

\section{METHODS}

We conducted a cross-sectional survey among doctors practicing modern medicine at Government institutions, private hospitals and private clinics in the city corporation of Trivandrum (new name Thiruvananthapuram) district, the capital district of Kerala, during June-September 2011. The district had a human development index (http://www.undp. org) score of 0.773 (same as the average score for the state as a whole), making it fairly representative of the state. ${ }^{13}$

Anticipating a PA prevalence of $20 \%,{ }^{14}$ the worst acceptable result as $13 \%$, an $\alpha$ error of $5 \%$ and a non-response rate of $15 \%$, the sample size was estimated to be 145 . We considered doctors who were more likely to not only play a central role in medical and behavioural management of chronic diseases/ conditions, but also give advice on PA to patients and doctors without any specialty training. The specialties included were cardiology, endocrinology, paediatrics and general (internal) medicine. Study participants were selected by the multistage random sampling method. Healthcare institutions in the city corporation were identified from the District Medical Office, Registry of the Indian Medical Association and telephone directory. Out of a total of 104 healthcare institutions (comprising 31 government institutions, 37 private hospitals and 36 single doctor private clinics), 70 institutions were randomly selected (22 government institutions, 29 private hospitals and 19 single doctor private clinics). Doctors from each of the selected institutions were listed initially. A total of 177 doctors were selected randomly, with the number of doctors 
from each of the hospitals being proportionate to the size. Among them, $146(82.6 \%)$ consented and participated in the study.

Ethical clearance for the study was obtained from the Institutional Ethics Committee of the Sree Chitra Tirunal Institute for Medical Sciences and Technology, Trivandrum. Informed written consent was obtained before the start of the study.

The entire survey was conducted by one of the authors (LP) using a self-administered, semistructured questionnaire. Information was collected on the sociodemographic characteristics, place of work, self-reported height, weight, waist circumference, diabetes, hypertension, heart diseases, asthma dyslipidaemia, awareness on the WHO recommendation for PA and beneficial roles of PA for prevention of NCDs. PA in different domains was assessed using the Global Physical Activity Questionnaire (GPAQ). Low, moderate and vigorous PA were defined as <600, 600-2999 and $\geq 3000$ MET min/week, respectively. ${ }^{15}$ Information on the use of exercise facility, membership in a health club, motivation for PA, use of exercise equipment at home, previous participation in sports activity, eating a healthy diet (subjective, self-report), belief that an own healthy lifestyle can influence the advice practice and number of patients consulted per day was also collected. We also surveyed how often doctors (1) asked about PA and (2) gave advice/prescribed exercise.

Overweight was defined as body mass index (BMI) $\geq 25 \mathrm{~kg} / \mathrm{m}^{2}$ and obesity as $\geq 30 \mathrm{~kg} / \mathrm{m}^{2}$. Abdominal obesity was defined as waist circumference $\geq 90 \mathrm{~cm}$ in men and $\geq 80 \mathrm{~cm}$ in women. ${ }^{16}$

Data were analysed using SPSS V.17.0 (SPSS Inc, USA). Analysis on the level of PA was performed according to the GPAQ analysis protocol. ${ }^{15}$ Stepwise multivariate logistic regression analysis with the forward-likelihood ratio method was performed for finding the predictors of self-reported PA and PA counselling practices. Variables which are known to be risk factors for PA and all those found to be significant in bivariate analysis $(p<0.05)$ were included in the multivariate analysis model.

\section{RESULTS}

The mean age of the doctors was $43 \pm 11.3$ years (range $25-66$ ). Among the total 146 doctors, 98 (67.1\%) were specialists. Of them, $40.8 \%$ were general medicine specialists, $23.5 \%$ paediatricians, $21.4 \%$ cardiologists and $14.3 \%$ endocrinologists. The background characteristics of the study sample are presented in table 1 .

Half of the doctors (51.4\%) were familiar with the WHO recommendation for PA for adults. Nearly one-fourth of the doctors (24.7\%) reported that they had attended classes/sessions on PA in medical college and $26 \%$ reported that they received formal training for PA counselling. A large majority of the doctors $(78 \%)$ agreed that there is a role for PA in primary and secondary (91.1\%) prevention of chronic diseases. All the participants agreed that PA has a beneficial role in the prevention of heart diseases, obesity and diabetes. Over half of them (52\%) reported the beneficial role of $\mathrm{PA}$ in depression, $22.6 \%$ in chronic respiratory disease and $19.8 \%$ in cancers. Eighty-one per cent of doctors perceived the importance of exercise apart from daily work-related activities. However, only 34.9\% reported that they made a conscious effort to perform regular exercise.

The mean self-reported PA of the doctors was 464 \pm 40 MET $\mathrm{min} /$ week. Vigorous PA was not reported by any of the doctors. Moderate PA was reported by $37.7 \%$ (men 38.4\%; women
$36.7 \%$ ) and $62.3 \%$ reported being inactive (men 61.6\%; women $63.3 \%$ ).

Sixty-six per cent of the doctors reported that environmental facilities such as parks, grounds, footpaths and gymnasiums or sports clubs were available near their house for exercise. Among them, $56.7 \%$ reported using them. More than half of the doctors $(54.8 \%)$ considered that their neighbourhood was safe to go for a walk at any time of the day and 51.4\% reported that the neighbourhood traffic interfered with walking or cycling. The main barriers to PA were reported to be lack of time $(54.8 \%)$, lack of motivation $(47.3 \%)$ and being too tired (18.5\%). The facilitators for PA were self-motivation (74\%), encouragement by family members $(24.7 \%)$ and support from friends, neighbours or colleagues $(9.6 \%)$.

More than half of the doctors $(52.1 \%)$ had some kind of exercise equipment at home. Of them, $47.4 \%$ reported using it regularly. Forty-three per cent of them were involved in outdoor games at school or college. Leisure time activity was the main component of the overall PA among doctors. Walking in their leisure time for the purpose of exercise was the most common activity (78\%) among doctors who were active at leisure. However, job-related and travel-related PA were largely absent. Sixty-one per cent of the doctors reported watching TV for less than $1 \mathrm{~h} /$ day and $55.5 \%$ reported using the computer for less than $1 \mathrm{~h} /$ day. Sixty-six per cent of the doctors reported eating a healthy diet.

Results of stepwise multivariate logistic regression analysis on predictors of moderate PA are presented in table 2.

The variables included but dropped during stepwise logistic regression analysis were age, sex, previous participation in sports activities, membership in health clubs and eating a healthy diet.

Sixty-two (42.5\%) doctors reported that they always 'asked' their patients about their current PA levels and $46.6 \%$ doctors

Table 1 Background characteristics of the study sample

\begin{tabular}{|c|c|c|c|}
\hline Characteristics & $\begin{array}{l}\text { Male (N=86) } \\
\text { n (\%) }\end{array}$ & $\begin{array}{l}\text { Female }(\mathrm{N}=60) \\
\mathrm{n}(\%)\end{array}$ & $\begin{array}{l}\text { Total }(\mathrm{N}=146) \\
\mathrm{n}(\%)\end{array}$ \\
\hline \multicolumn{4}{|l|}{ Age group } \\
\hline$<40$ & $39(45.3)$ & $22(36.7)$ & $61(41.8)$ \\
\hline $40-59$ & $37(43.0)$ & $31(51.7)$ & $68(46.6)$ \\
\hline $60+$ & $10(11.6)$ & 7 (11.7) & $17(11.6)$ \\
\hline \multicolumn{4}{|l|}{ Category of practice } \\
\hline General practitioners & $29(33.7)$ & $19(31.7)$ & $48(32.9)$ \\
\hline Specialists & $57(66.3)$ & $41(68.3)$ & $98(67.1)$ \\
\hline \multicolumn{4}{|l|}{ Workplace } \\
\hline Government hospital & $30(34.9)$ & $26(43.3)$ & $56(38.4)$ \\
\hline Private hospital & $56(65.1)$ & $34(56.7)$ & $90(61.6)$ \\
\hline \multicolumn{4}{|l|}{ Marital status } \\
\hline Currently married & $71(82.6)$ & $43(71.7)$ & $114(78.1)$ \\
\hline Others & $15(17.4)$ & $17(28.3)$ & $32(21.9)$ \\
\hline Overweight* & $48(55.8)$ & $24(40.0)$ & $72(49.3)$ \\
\hline Abdominal obesity* & $45(52.3)$ & $31(51.7)$ & $76(52.5)$ \\
\hline Diabetes* & $30(34.9)$ & $13(21.7)$ & $43(29.5)$ \\
\hline Hypertension* & $21(24.4)$ & $12(20.0)$ & $33(22.6)$ \\
\hline Dyslipidaemia* & $23(26.7)$ & $11(18.3)$ & $34(23.3)$ \\
\hline $\begin{array}{l}\text { Tobacco use in the last } \\
30 \text { days }\end{array}$ & $16(18.6)$ & 0.0 & $16(11.0)$ \\
\hline $\begin{array}{l}\text { Alcohol use in the last } \\
30 \text { days }\end{array}$ & $35(40.7)$ & 0.0 & $35(24.0)$ \\
\hline
\end{tabular}

Patra L, et al. Br J Sports Med 2015;49:413-416. doi:10.1136/bjsports-2012-091995 
Table 2 Predictors of moderate physical activity: results of stepwise multivariate logistic regression analysis

\begin{tabular}{|c|c|c|}
\hline Variable & $\begin{array}{l}\text { Moderate physical } \\
\text { activity }(\%)\end{array}$ & $\begin{array}{l}\text { Adjusted OR } \\
(95 \% \mathrm{Cl})\end{array}$ \\
\hline \multicolumn{3}{|c|}{ Use of exercise facility in the neighbourhood } \\
\hline No & 28.6 & Reference \\
\hline Yes & 52.7 & 2.36 (1.11 to 5.02$)$ \\
\hline \multicolumn{3}{|c|}{ Received motivation for PA } \\
\hline No & 23.2 & Reference \\
\hline Yes & 50.6 & 4.01 (1.82 to 8.86$)$ \\
\hline \multicolumn{3}{|c|}{ Use of exercise equipment at home } \\
\hline No & 30.0 & Reference \\
\hline Yes & 61.1 & 3.97 (1.68 to 9.36$)$ \\
\hline
\end{tabular}

always gave 'verbal advice'. One-fourth of the doctors $(25.3 \%)$ 'always asked and advised' their patients regarding PA. There was no significant difference between the general practitioners and the specialists in the 'ask and advise practices for PA $(p=0.690)$. Results of stepwise multivariate logistic regression analysis on predictors of doctors always asking and advising on PA are presented in table 3.

\section{DISCUSSION}

The mean PA level among doctors in our study (464 MET min/ week) was lower than (1227 MET min/week) that reported from the only other Indian study among young doctors. ${ }^{12}$ The higher level of PA reported in the above study could be due to the selection of the doctors who volunteered. The PA level among our doctors was also much lower than that reported in a study among young family physicians in Estonia $(2871 \pm 2470$ MET min/week). ${ }^{17}$

The moderate PA level in our study was similar to the PA level (grouped as active and sedentary) among primary care doctors in Bahrain $(29.7 \%)^{18}$ and Nigeria (38.1\%). ${ }^{19}$ Doctors from Bahrain reported a higher prevalence of PA than the general population. The PA level among doctors in our study was lower than that reported by the adult population (15-64 years) in the Indian state of Kerala. ${ }^{14}$ The lower level of PA among doctors could be one of the reasons for the higher

Table 3 Predictors of doctors' always ask and advise on physical activity: results of stepwise multivariate logistic regression analysis

\begin{tabular}{lll}
\hline Variable & Always ask and advise (\%) & Adjusted OR $(95 \% \mathrm{Cl})$ \\
\hline $\begin{array}{l}\text { Previous participation in sports activities } \\
\text { No }\end{array}$ & 14.3 & Reference \\
Yes & 40.3 & $4.22(1.77$ to 10.04$)$ \\
Number of patients consulted per day & \\
$>30$ & 08.8 & Reference \\
$\leq 30$ & 30.4 & $5.35(1.41$ to 20.25$)$ \\
Believes that own healthy lifestyle can influence advice practice \\
No & 06.4 & Reference \\
Yes & 34.3 & 9.13 (2.49 to 33.41) \\
\hline
\end{tabular}

The variables included but dropped during stepwise logistic regression analysis were age, sex, workplace, category of practice, level of PA and knowledge on WHO recommendation for $\mathrm{PA}$.

PA, physical activities. prevalence of some of the NCDs among them. For example, self-reported diabetes among our doctors (29.5\%) was much higher than the $16.2 \%$ diabetes prevalence estimated by fasting glucose in the above Kerala study conducted in the same district, although the mean age of men (39.6 years) was slightly lower than that of our doctors. Alcohol use among our male doctors $(40.7 \%)$ was much higher than among the male general population (31.1\%). However, tobacco use among male doctors $(18.6 \%)$ was less than half reported among the male general population $(50.3 \%)^{14}$ as reported earlier. ${ }^{20}$

Our data extend previous findings ${ }^{21}$ that motivation for PA behaviour was a predictor for PA. Other correlates of moderate PA among doctors in our study were use of exercise equipment at home and use of exercise facility in the neighbourhood. A positive association between the level of PA and the presence or proximity to exercise facilities, ${ }^{22}$ and exercise equipment at home ${ }^{23}$ was already reported.

Similar to the findings among doctors in the USA $(28 \%),{ }^{24}$ our study demonstrated that only one-fourth of the doctors always asked and advised on PA. The proportion of doctors who always advised was more than the proportion of doctors who always asked about PA, which was similar to that reported on 'ask and advice' practices on tobacco in India. ${ }^{25}$ Doctors who believed that their own healthy lifestyle could influence advice practice were more likely to always ask and advise their patients on PA. An earlier study reported that doctors who themselves led a healthy lifestyle were more likely to counsel on PA. ${ }^{26}$ For example, $30 \%$ of doctors with a normal BMI spoke with patients about losing weight, compared with $18 \%$ of overweight or obese doctors. $^{27}$

Health promotion or disease prevention activities are highly relevant when investigating topics related to doctor-patient interaction, that is, the number of patients seen per day and the time spent per patient. ${ }^{28}$ Patient load was found to be a deterrent for counselling practices in our study. A previous study also reported that patient load was a factor that restricted primary care doctors from delivering preventive and chronic disease services. $^{29}$

Although we expected better counselling practices by the selected specialist doctors compared with the general practitioners, we did not find any significant difference in counselling (ask and advice practice) between these two groups of doctors. Why the specialist doctors in our sample did not offer better counselling needs to be further explored.

\section{LIMITATION}

PA was not validated using an objective measure such as an accelerometer. However, the GPAQ validation study demonstrated a strong association between self-reports and actual PA. ${ }^{30}$

\section{CONCLUSION}

The major correlates of PA were the motivation for PA, use of exercise equipment at home and exercise facility in the neighbourhood. Correlates of 'always ask and advise' for PA were the belief that one's own healthy lifestyle can influence 'ask and advice' practice, patients' overload and previous participation in sports activities. PA needs to be integrated into the primary healthcare system. As per WHO, doctors' routine enquiries about PA and advice on skill building to change behaviour can reach a large proportion of population and can be a costeffective intervention. ${ }^{31}$ 


\section{What are the new findings?}

- Moderate physical activity (PA) was reported by $37.7 \%$ of the doctors and the remaining reported being inactive.

- The major correlates of PA were motivation for PA, use of exercise equipment at home and exercise facility in the neighbourhood.

- Twenty-five per cent of the doctors always asked and advised their patients on PA.

- Correlates of 'always ask and advise' for PA were the belief that one's own healthy lifestyle can influence 'ask and advice' practice, patients' overload and previous participation in sports activities.

\section{How might it impact on clinical practice in the near} future?

- More doctors are likely to 'always ask and advise' their patients on PA.

- In order to 'ask and advise' on PA, doctors may spend more time with each patient.

- Doctors may limit the number of patients to less than $30 /$ day.

Acknowledgements The authors would like to acknowledge all the doctors who participated in this study.

Contributors All the authors contributed to the writing of the manuscript, and read and approved the final draft of the manuscript. The contribution of each of the authors is listed below: LP contributed to the conception, design, acquisition of data and writing of the first draft of the manuscript; GKM contributed to the analysis and interpretation of data and revision of the manuscript with critical contribution for intellectual content; EM contributed to the conception, design and revision of the manuscript with critical contribution for intellectual content; KRT contributed to the conception, design and revision of the manuscript with critical contribution for intellectual content, and also approved the final draft of the version to be published.

Competing interests None.

Ethics approval Institutional Ethics Committee of the Sree Chitra Tirunal Institute for Medical Sciences and Technology, Trivandrum.

Provenance and peer review Not commissioned; externally peer reviewed.

\section{REFERENCES}

1 World Health Organisation. Physical inactivity: a Global Public Health Problem. Geneva: WHO, 2011.

2 Global Advocacy for Physical Activity (GAPA) the Advocacy Council of the International Society for Physical Activity and Health (ISPAH). NCD prevention: investments that work for physical activity. Br I Sports Med 2012;46:709-12.

3 Beach MC, Roter DL, Wang NY, et al. Are physicians' attitudes of respect accurately perceived by patients and associated with more positive communication behaviors? Patient Educ Couns 2006;62:347-54.

4 Naithani S, Gulliford M, Morgan M. Patients' perceptions and experiences of 'continuity of care' in diabetes. Health Expect 2006:9:118-29.
5 Falvo D, Woehlke P, Deichmann J. Relationship of physician behaviour to patient compliance. Patient Couns Health Educ 1980;2:185-8.

6 Walsh JM, Swangard DM, Davis T, et al. Exercise counseling by primary care physicians in the era of managed care. Am J Prev Med 1999;16:307-13.

7 Howe M, Leidel A, Krishnan SM, et al. Patient-related diet and exercise counseling: do providers' own lifestyle habits matter? Prev Cardiol 2010;13:180-5.

8 Lobelo F, Duperly J, Frank E. Physical activity habits of doctors and medical students influence their counselling practices. Br J Sports Med 2009:43:89-92.

9 McKenna J, Naylor PJ, McDowell N. Barriers to physical activity promotion by general practitioners and practice nurses. Br J Sports Med 1998;32:242-7.

10 Jacobson DM, Strohecker L, Compton MT, et al. Physical activity counseling in the adult primary care setting - position statement of the American College of Preventive Medicine. Am J Prev Med 2005;29:158-62.

11 Patel V, Chatterii S, Chisholm D, et al. Chronic diseases and injuries in India. Lancet 2011:377:413-28.

12 Gandhi H, Vaishali K, Prem K, et al. A survey on physical activity and noncommunicable disease risk factors among physicians in Tertiary care hospital, Mangalore. Natl J Community Med 2012;3:7-13.

13 Government of Kerala. Human Development Report 2005. Trivandrum, Kerala: State Planning Board, 2006.

14 Thankappan KR, Shah B, Mathur P, et al. Risk factor profile for chronic non communicable diseases: results of a community — based study in Kerala, India. Indian J Med Res 2010;131:53-63.

15 Guidelines for Data Processing and Analysis of the Global Physical Activity Questionnaire (GPAQ). http://www.who.int/chp/steps/resources/GPAQ Analysis Guide. (accessed 10 Aug 2012).

16 International Diabetes Federation. The IDF consensus worldwide definition of the metabolic syndrome. Belgium: IDF, 2006.

17 Suija K, Pechter U, Maaroos J, et al. Physical activity of Estonian family doctors and their counselling for a healthy lifestyle: a cross-sectional study. BMC Fam Pract 2010;11:48.

18 Bahram S, Abbas B, Kamal J, et al. Leisure-time physical activity habits among physicians. Bahrain Med Bull 2003;25:80-2.

19 Aghaji MN. Doctors lifestyle in Enugu, Nigeria. East Afr Med J 2000;77:480-4.

20 Mohan S, Pradeepkumar AS, Thresia CU, et al. Tobacco use among medical professionals in Kerala, India: the need for enhanced tobacco cessation and control efforts. Addict Behav 2006:31:2313-18.

21 Jepson R, Harris FM, Bowes A, et al. Physical activity in South Asians: an in-depth qualitative study to explore motivations and facilitators. PLOS ONE 2012; e45333.

22 Eriksson U, Arvidsson D, Sundquist K. Availability of exercise facilities and physical activity in 2037 adults: cross-sectional results from the Swedish neighborhood and physical activity (SNAP) study. BMC Public Health 2012;12:607.

23 Jakicic JM, Wing RR, Butler BA, et al. The relationship between presence of exercise equipment in the home and physical activity level. Am J Health Promot 1997;11:363-5

24 Glasgow RE, Eakin EG, Fisher EB, et al. Physician advice and support for physical activity: results from a national survey. Am J Prev Med 2001:21:189-96.

25 Thankappan KR, Pradeepkumar AS, Nichter M. Doctors' behaviour \& skills for tobacco cessation in Kerala. Indian J Med Res 2009;129:249-55.

26 Frank E, Rothenberg R, Lewis C, et al. Correlates of physicians' prevention-related practices. Findings from the women physicians' health study. Arch Fam Med 2000;9:359-67.

27 Bleich SN, Bennett WL, Gudzune KA, et al. Impact of physician BMI on obesity care and beliefs. Obesity (Silver Spring) 2012:20:999-1005

28 Oberg EB, Frank E. Physicians' health practices strongly influence patient health practices. J R Coll Physicians Edinb 2009:39:290-1.

29 Ridsdale L, Morris R, Ridsdale J. Study on the effect of time availability on the consultation. J R Coll Gen Pract 1989:39:488-91.

30 Bull FC, Maslin TS, Armstrong T. Global physical activity questionnaire (GPAQ): nine country reliability and validity study. J Phys Act Health 2009;6:790-804.

31 World Health Organization. Interventions on diet and physical activity: what works: summary report. Geneva: WHO, 2009. 